\title{
CORRELATION BETWEEN MANDIBULAR ARCH WIDTH AND THE PARAMETERS OF THE SKULL
}

\section{Evgeniya Efimova $^{1 凶} \mathbb{D}^{D}$, Grigory Snigur ${ }^{1,2}$ (D), Yury Efimov ${ }^{1}{ }^{(D)}$, Aleksander Krayushkin ${ }^{1}$ (D), Sergey Fedorov ${ }^{1}$}

\author{
${ }^{1}$ Volgograd State Medical University, Volgograd, Russia \\ 2 "Biomeditsina" Youth Innovation Technology Center, Volgograd, Russia \\ $\triangle$ evgenia_ey@mail.ru
}

ABSTRACT - 110 certified male skull samples were studied to identify the relationship between mandibular arch width and skull type. This can facilitate the determination of a physiological norm and avoidance of diagnostic and treatment errors.

\section{NTRODUCTION}

For appropriate diagnosis and devising an adequate and rational treatment plan, it is essential to perform linear measurements of dental arches to establish correlations between arch width and skull type. Data on dimensions of dental arches obtained from skull samples might give more insight into their structure and correlation with skull type, which is of importance for both comparative basic medical research and personalized medicine.

\section{MATERIALS AND METHODS}

We analyzed 110 certified male skull samples to identify the relationship between mandibular arch width and skull type. The cranial, or cephalic index was referred to as the ratio of the transverse to the longitudinal diameters of the skull: mesocephalic skull type 42 samples, brachycephalic skull type 36 samples and dolichocephalic skull type 32 samples.

Measurements of the vestibular and lingual surfaces of dental arches showed that the arches width was lesser than cranial vault width and cranial base width and did not depend on the skull type $(\mathrm{p}<0.001$; $r=+0.73$ ). It was revealed that the upper face height of all samples was greater than mandibular arch width vestibular surfaces at the level of the canines and premolars $(\mathrm{p}<0.001 ; \mathrm{r}=+0.46-+0.52)$. The height of the dentoalveolar part of the upper jaw was statistically significantly inferior to the dental arches width at all measurement levels $(\mathrm{p}<0.001 ; \mathrm{r}=+0.23)$.

\section{CONCLUSION}

The study of the relationship between dental arch widths and skull type is required for adequate interpretation of the studied values. This can assist in determining physiological norm more specifically, thus resulting in a decline of potential diagnostic and treatment errors in patients with dentofacial deformities.

\section{REFERENCES}

1. KorobkeEv A.A., Domenyuk D.A., ShKarin V.V. ET AL. Anatomical features of the interdependence of the basic parameters of the dental arches of the upper and lower jaws of man. Medical News of North Caucasus. 2018; 13 (1.1):66-69. https://doi.org/10.14300/ mnnc.2018.13019

2. Trivedi H., Azam A., Tandon R. et al. Correlation between morphological facial index and canine relationship in adults. Dental Research and Management.2017;2:31-35. https://doi.org/10.33805/25726978.107

3. Sinhorini P.A., Costa I.A.P., Lopez-CAPP T.T. ET AL. Comparative analysis of four morphometric methods for sex estimation: A study conducted on human skulls. Legal Medicine.2019;39:29-34. https:// doi.org/10.1016/j.legalmed.2019.06.001 